\title{
Metodologia para priorização de ações em aglomerados subnormais considerando os riscos de deslizamentos e inundações e as condições de moradia
}

\author{
Methodology for prioritizing actions in slums considering \\ risks of landslides and flooding, and housing conditions
}

\author{
Maria Odete Teixeira do Nascimento \\ Geógrafa e Mestre em Engenharia Urbana pela Universidade Federal da Paraíba (UFPB) - João Pessoa (PB), Brasil. \\ Professora de Geografia, Secretaria de Educação do Estado da Paraíba - João Pessoa (PB), Brasil.
}

\begin{abstract}
Hamilcar José Almeida Filgueira
Engenheiro Agrícola pela UFPB e Doutor em Recursos Naturais pela Universidade Federal de Campina Grande (UFCG). Professor Associado I da UFPB João Pessoa (PB), Brasil.
\end{abstract}

Tarciso Cabral da Silva

Engenheiro Civil pela UFPB. Doutor em Engenharia Civil pela Universidade de São Paulo (Poli/USP). Professor Titular da UFPB - João Pessoa (PB), Brasil.

\section{Resumo}

Os problemas das áreas de riscos de desastres nas cidades brasileiras, principalmente os hidrometeorológicos, como inundações, e os geológicos, como deslizamentos, estão normalmente relacionados a determinantes socioeconômicos e ambientais. Assim, a busca por metodologias para compreender as vicissitudes da dinâmica do ambiente urbano torna-se fundamental para programar ações que minimizem essa problemática. Este artigo tratou da proposição de uma metodologia integradora multiobjetivo, visando à priorização de ações de melhoria habitacional ou relocação de moradias de aglomerados subnormais em áreas de riscos. Apresentou-se resumidamente a análise realizada em três áreas na cidade de João Pessoa, no estado da Paraíba. Os resultados indicaram como a mais apropriada opção a relocação de moradias para 4,5\% do total, sendo que para 14,1\% delas indicou-se melhoria habitacional.

Palavras-chave: riscos ambientais; condições de moradia; aglomerados subnormais.

\begin{abstract}
The problems regarding disaster risk areas in Brazilian cities, mainly hydrometeorological ones, such as flooding, as well as geological, like landslides, are typically related to socioeconomic and environmental determinants. Therefore, the search for methodologies aiming at understanding the vicissitudes of the dynamics in urban environment is essential in order to develop actions that may minimize these issues. This article proposed a novel integrated multiobjective methodology with the purpose of prioritizing actions for housing improvements or relocation of slums settlements in risk-prone areas. In addition, a brief analysis of three areas in the city of João Pessoa, state of Paraíba, Brazil, was presented. The results indicated that the best option is housing relocation for $4.5 \%$ of the total dwellings surveyed, and for $14.1 \%$ of them, housing improvement was proposed.
\end{abstract}

Keywords: environmental risks; housing conditions; slums settlements.

\section{Introdução}

O crescimento da população nos centros urbanos tem provocado mudanças indesejáveis no que diz respeito ao acesso à moradia apropriada. No Brasil, a partir dos anos 1960, tem-se verificado que a oportunidade de se viver com qualidade de vida nas cidades não se apresenta de forma igual para todos. Parte da população, principalmente a parcela menos favorecida economicamente, passou a ocupar áreas sem infraestrutura adequada e que estão sujeitas a risco de desastres relacionados a fenômenos naturais. Esse aumento do número de pessoas vivendo em áreas de risco de desastres e em moradias impróprias tem sido uma das características negativas do processo de urbanização e crescimento de grande parte das cidades brasileiras. 
A ocorrência de desastres relacionados a fenômenos naturais está relacionada à tendência do meio devido às suas características geoambientais e à vulnerabilidade do sistema social. Vargas (2002) definiu risco de desastre como a magnitude provável de dano a um ecossistema específico ou a alguns de seus componentes, em um período determinado ante a presença de uma atividade com potencial perigoso. Esse autor também apresentou a vulnerabilidade como a propensão interna de um ecossistema ou de alguns de seus componentes de sofrer dano na presença de uma determinada força ou energia potencialmente destrutiva. Sabe-se que um fenômeno natural não causa desastres por si só. Existirão desastres, apenas se houver riscos e vulnerabilidades.

As pesquisas científicas voltadas para o estudo dos riscos de desastres relacionados aos fenômenos naturais, levando-se em conta os aspectos sociais, evoluíram consideravelmente nos últimos anos. Análises visando suprir a comunidade de usuários de informações para o benefício da sociedade melhoram a qualidade das tomadas de decisões.

O Ministério das Cidades avalia o risco como a relação entre a possibilidade de ocorrer um determinado processo ou fenômeno e a magnitude dos danos ou das consequências sociais e/ou econômicas sobre um elemento, um grupo ou uma comunidade (BRASIL, 2006). Riscos geológicos são referentes aos fenômenos terrestres naturais associados a processos endógenos tectônicos ou exógenos como os movimentos de massa, citando-se como exemplo os deslizamentos de terra, as quedas de rochas e as corridas de lama. Os riscos hidrometeorológicos são relativos a processos naturais ou fenômenos de ordens atmosférica, hidrológica e oceânica (inundações, fluxos de detritos ou de lama, erosão hídrica e costeira, tempestades, entre outros).

A elaboração deste trabalho teve como intuito servir de base às administrações municipais, no intuito de fornecer melhores instrumentos metodológicos para o auxilio à tomada de decisões, visando às requalificações urbana e ambiental dos aglomerados subnormais. Desse modo, os riscos de desastres ambientais e a qualidade da habitação eram as variáveis consideradas mais importantes (NASCIMENTO, 2009). Destacaram-se como riscos principais os de natureza geológico-geotécnica, ou simplesmente geológicos, e os hidrometeorológicos, além das condições de moradia.

Buscou-se, então, a melhor situação expressa por variáveis que retratem o conforto e a higidez, representada pelas condições de moradia, além da sua segurança estrutural ante a ocorrência de fenômenos naturais. Nesse sentido, propõe-se uma metodologia multiobjetivo de análise integrada das variáveis condições das moradias e grau de risco, que permite a tomada de decisão sobre as melhores intervenções físicas a serem feitas nos aglomerados urbanos subnormais, caso seja decidido realizar políticas de requalificação.

Três aglomerados subnormais na cidade de João Pessoa, capital do estado da Paraíba, foram escolhidos para realizar a aplicação da metodologia proposta: os aglomerados subnormais Saturnino de Brito, Renascer I e Santa Emília de Rodat.

\section{Metodologia}

A metodologia apresentada neste trabalho consistiu: na determinação dos valores de variáveis associadas a riscos geológicos ou hidrometeorológicos e às condições de moradia de aglomerados subnormais, plotando-as, em um gráfico cartesiano; no cruzamento das mesmas, segundo a posição no sistema de coordenadas xy, em que x é a variável relativa à condição de moradia e y os riscos associados ao local, com a análise integrada, o que permite a interpretação da qualidade da moradia quanto a esses aspectos específicos; na sequência, tem-se a indicação, em um quadro, das ações a serem prescritas e o respectivo grau de prioridade conforme a posição relativa das variáveis no gráfico cartesiano. Assim, considerou-se como condição ótima, a moradia que apresentou os valores máximos de avaliação de tais variáveis representativas. Ao contrário, a pior condição é apontada pelos valores mais desfavoráveis daquelas relativas à condição de moradia e ao risco local.

Os riscos pesquisados e passíveis de ocorrência na área do estudo são de natureza geológica (deslizamentos de encostas) e hidrometeorológica (inundações). Para os riscos referentes a inundações, buscou-se identificar os cursos d'água na área de estudo, verificando-se a ocupação territorial em suas margens. A metodologia para classificar os riscos está descrita em publicação do Ministério das Cidades (BRASIL, 2006).

Quanto às condições de moradia, foram realizados levantamentos nos aglomerados em estudo, no sentido de se avaliar, segundo a metodologia estabelecida por Silva (2006), os aspectos referentes à densidade e à qualidade da habitação. Essas duas variáveis, riscos e condições de moradia, estão associadas a fim de serem definidas as melhores ações que permitam a adoção de medidas para eliminar ou minimizar os problemas em pauta, de forma racional e integrada.

\section{Modelo proposto}

\section{Avaliação dos riscos de deslizamentos e inundações}

Para avaliar os riscos geológicos relativos a deslizamentos de encostas, realizou-se a caracterização dos aglomerados subnormais por grupos de moradia, verificando-se: o tipo de talude, o material da habitação, a inclinação da encosta, a distância da moradia ao topo e à base dos taludes e o ângulo de inclinação do terreno, conforme a metodologia descrita em Brasil (2006). Por meio do enquadramento de diversos critérios relevantes especificados nessa metodologia, classificam-se os riscos em quatro graus que levam em consideração a sua magnitude: muito alto (R4), alto (R3), médio (R2) e baixo ou sem risco (R1).

Os riscos geológicos classificados como muito alto são caracterizados como alta potencialidade dos processos de deslizamentos de encostas, sinais evidentes de instabilidade dos terrenos, presença 
de trincas nas moradias, postes de iluminação e árvores inclinadas, entre outros indicativos. Por outro lado, os do tipo baixo ou sem risco distinguem-se pela ausência de sinais de instabilidade dos terrenos, constatando-se baixa potencialidade para processos de deslizamentos.

No entanto, os critérios de classificação de riscos hidrometeorológicos relativos às inundações referem-se: a tipologias de processos hidrológicos (enchente e inundação lenta de planícies fluviais, enchente e inundação com alta energia de escoamento, entre outros); ao padrão construtivo das habitações (material de construção das moradias, se considerado de alto padrão ou alternativo) e à distância das moradias ao eixo do curso d'água. A partir da definição dos tipos de riscos, a metodologia descrita em Brasil (2006) permitiu o enquadramento da área em estudo nos cenários de riscos: muito alto (R4), alto (R3), médio (R2) e baixo ou sem risco (R1). Aqueles classificados como muito alto são referentes a cursos d'água com grande potencial para causar danos sociais pela frequência de ocorrência, ou seja, pelo menos três eventos significativos em cinco anos. Já aqueles considerados como baixos relacionam-se ao pequeno potencial para causar danos com baixa frequência de ocorrência dos eventos de inundação (nenhum registro significativo em pelo menos cinco anos).

\section{Avaliação das condições de moradia}

A metodologia desenvolvida por Silva (2006) define o Indicador de Condições de Moradia (ICM) como função de diversos subindicadores pertinentes à qualidade do domicílio.

Considera-se como principais variáveis para avaliar a higidez dos domicílios: condições físicas e tipologia construtiva das habitações, condições sanitárias das habitações e espaço interno dos domicílios. Além dessas variáveis também se leva em consideração o número de pessoas residentes em cada habitação a fim de avaliar a densidade habitacional.

Portanto, para se encontrar o ICM, calculam-se os valores de dois subindicadores: o Índice de Densidade Habitacional (Idh) e o Índice de Qualidade Habitacional (Iqh). Assim, a determinação do Idh é realizada pela razão entre o número de moradores do domicílio e a área da habitação; e a do Iqh, baseia-se na qualidade construtiva (tipo de revestimento de piso e paredes, coberta do domicílio) e nas condições de infraestrutura sanitária (existência de banheiro, cozinha, pia e bacia sanitária). O método de Silva (2006) especificou tabelas para os diversos critérios de análise e indicou valores numéricos (sendo $0 \mathrm{a}$ pior condição e 1 a melhor), segundo a análise a ser feita na moradia em questão. Por meio destes subindicadores torna-se possível avaliar a qualidade, ou seja, a condição de habitabilidade da moradia.

$\mathrm{O}$ valor do ICM é então obtido pela expressão ICM=(Idh+Iqh)/2, e varia de 0 (condições mais desfavoráveis possíveis ou insalubres) a 1 (condições muito boas de moradia ou salubres). Em seguida, faz-se o enquadramento do domicílio de cada aglomerado subnormal como apresentado no Quadro 1, segundo Silva (2006).

\section{Metodologia para análise integrada dos indicadores de risco e condições de moradia}

A análise integrada dos riscos de deslizamentos e inundação e das condições de moradia para as comunidades estudadas foi efetuada lançando-se mão de uma técnica multiobjetivo de cruzamento dos indicadores, adaptada para este trabalho por Nascimento (2009), com base na metodologia de avaliação ambiental integrada de bacias hidrográficas segundo a Organização das Nações Unidas para a Educação, a Ciência e a Cultura (UNESCO, 1987). No trabalho de Nascimento (2009), foi proposto um gráfico bidimensional que foi utilizado para visualizar os valores conjuntos das duas variáveis independentes indicadoras de riscos e das condições de moradia. Adotou-se a escala de riscos em ordem decrescente no eixo vertical, ao contrário daquela de condições de moradia na horizontal, em ordem crescente.

A Figura 1 permite enquadrar de forma conjunta as diversas combinações de riscos e condições de moradias. Mostra também o campo dos estados possíveis das variáveis envolvidas, permitindo-se inferir, a partir da posição expressa por meio das coordenadas dos pontos representativos das condições de moradia e dos graus de

\section{Quadro 1 - Situação de salubridade por faixa de pontuação.}

\begin{tabular}{|lc|}
\hline Situação da salubridade & Pontuação (\%) \\
\hline Insalubre & $0,00-25,00$ \\
\hline Baixa salubridade & $25,01-50,00$ \\
\hline Média salubridade & $50,01-75,00$ \\
\hline Salubre & $75,01-100,00$ \\
\hline
\end{tabular}

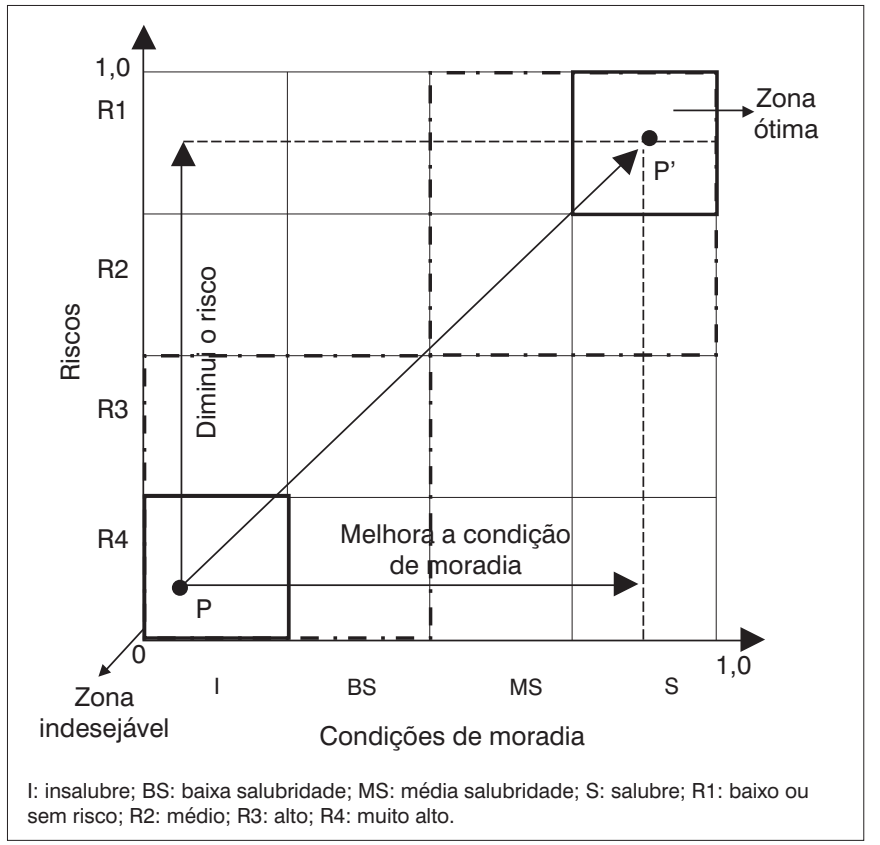

Figura 1 - Gráfico da base conceitual do modelo para definir ações a serem prescritas e prioridades, segundo o estado conjunto do grau de risco e das condições de moradia. 
riscos das habitações, as indicações das melhores ações a serem especificadas às intervenções nos aglomerados subnormais. Assim, são delimitadas 16 quadrículas referentes às áreas que indicam conjuntamente as quatro situações de riscos e as quatro das condições de moradia. Tem-se, por exemplo, a quadrícula I-R4 delimitando a zona indesejável equivalente ao risco muito alto e as moradias classificadas como insalubres, interpretadas como as piores condições. A zona ótima apresenta grau de risco baixo ou sem risco (R1) e condições de moradia classificadas como salubres (S), evidentemente, a melhor situação como está expressa. A distância do ponto P (na zona indesejável) até uma nova posição P' (na zona ótima) deve ser minimizada, o que aponta a ação a ser prescrita nos sentidos horizontal (melhora da condição de moradia) e/ou vertical (diminuir os riscos). Portanto, segundo o modelo proposto, a quadrícula MS-R2 significa moradia na condição de média salubridade em área equivalente ao risco classificado como médio e, desse modo, procede-se para as demais quadrículas. Aquelas consideradas intermediárias desfavoráveis são I-R3, BS-R3 e BS-R4, pois não apresentam distância pequena da zona ótima. As quadrículas MS-R1, MS-R2 e S-R2 são consideradas intermediárias favoráveis por se encontrarem a menores distâncias da zona ótima (Figura 1).

Deve ser ressaltado que foi escolhida uma forma particular de composição, segundo a metodologia de avaliação dos riscos adotada (BRASIL, 2006). Não há obtenção de um valor nessa metodologia, mas uma classificação de risco (R1 a R4). No entanto, para os riscos geológicos, os trechos situados em encostas mais inclinadas (evidentemente de maiores riscos) são plotados no gráfico abaixo dos trechos de menor inclinação, já que a escala do eixo vertical é inversa. Da mesma forma, para os de inundação, os trechos mais elevados em relação ao curso d'água (caso ocorra) recebem plotagem da classificação em posição mais alta, mesmo que na mesma quadrícula.

\section{Indicação de ações a partir da análise integrada dos indicadores de risco e condições de moradia}

A análise integrada descrita permite que se façam inferências das ações de interesse relativas à necessidade de melhorias da qualidade de vida dos moradores dos aglomerados subnormais. As ações a serem indicadas referem-se às medidas estruturais:

- eliminação ou redução de riscos ambientais por meio da implantação de medidas estruturais (construção de muros de contenção, canalização de rios, construção de diques marginais, entre outros) ou simplesmente relocação das moradias de áreas sujeitas a riscos para locais apropriados;

- melhoria das habitações, se situadas em áreas de baixo risco, compreendendo aprimoramento da qualidade habitacional e/ou ampliação de áreas do domicílio que resultem na diminuição da densidade habitacional.
Desse modo, permite-se, pela natureza das ações a serem especificadas nos aglomerados subnormais, o estabelecimento de prioridades, tendo em vista, essencialmente, a iminência de desastres ou a premência da necessidade de melhoria habitacional. No caso de relocação devido a altos riscos dos deslizamentos de encostas ou inundações, por exemplo, especifica-se grau de alta prioridade. Já no caso de riscos inexistentes e moradias salubres, a priorização de ações receberia grau nulo frente às demais nos outros casos.

As ações e os graus de prioridade, no Quadro 2, referem-se à posição relativa da moradia quanto à sua classificação indicada por meio das coordenadas cartesianas dos diversos pontos plotados no gráfico da Figura 1.

O enquadramento da moradia ou conjunto delas nas quadrículas da Figura 1 possibilita, além da indicação das ações a serem prescritas para o local das habitações para a sua melhoria, o seu grau de prioridade, classificado em ordem decrescente em: muito alto, alto, médio e baixo ou prioridade nula.

A fim de estabelecer graus de prioridade buscou-se a convergência de opiniões com consultas a especialistas, utilizando o método Delphi (PRESTES, 2004). Foram consultados 14 especialistas de áreas ligadas ao urbanismo, saneamento, arquitetura e construção e análise de riscos. Como resultado, para cada habitação, dependendo do grau de risco e da condição de moradia, obteve-se a indicação das decisões a serem tomadas relativamente às ações de caráter estrutural, bem como o seu grau de prioridade. Aquelas que foram indicadas para o aglomerado em análise são: relocação de moradias, eliminação ou redução de riscos, melhoria habitacional ou nenhuma. O detalhamento das ações e do grau de prioridade, segundo o grau de risco e a condição de moradia, encontra-se sumarizado no Quadro 2. Para a quantificação dos domicílios nas diversas áreas de riscos são utilizados dados oriundos de cartogramas elaborados para esse fim.

\section{Área de aplicação: características}

\section{Localização, aspectos naturais da cidade de João Pessoa e dos aglomerados}

As áreas estudadas situam-se na cidade costeira de João Pessoa, onde a pluviometria apresenta média anual de $1.700 \mathrm{~mm}$. A cidade tem enfrentado entre março e julho eventos diários de chuvas intensas. As precipitações maiores ou iguais a $20 \mathrm{~mm}$ e menores do que 50 mm têm frequência anual de 20 dias. Nesse período também ocorrem chuvas acima de $50 \mathrm{~mm}$, porém, com uma frequência de sete dias (ANJOS; COSTA; ANJOS, 2010). A formação litológica do município é caracterizada pela presença predominante de rochas sedimentares. A fácies do relevo predominante no município são os planaltos, isto é, os Baixos Planaltos Costeiros com forte presença de tabuleiros, como são regionalmente conhecidos. São feições morfológicas que 
Quadro 2 - Ações a serem indicadas conforme condição de moradia, risco e prioridade.

\begin{tabular}{|c|c|c|c|c|}
\hline Quadrícula & Graus de riscos & Condições de moradia & Indicação de ações & Grau de prioridade \\
\hline I-R4 & Muito alto & Insalubre & Relocação de moradias & Muito alto \\
\hline BS-R4 & Muito alto & Baixa salubridade & Relocação de moradias & Muito alto \\
\hline MS-R4 & Muito alto & Média salubridade & $\begin{array}{l}\text { Eliminação ou redução de riscos } \\
\text { Relocação de moradias }\end{array}$ & Muito alto \\
\hline S-R4 & Muito alto & Salubre & $\begin{array}{l}\text { Eliminação ou redução de riscos } \\
\text { Relocação de moradias }\end{array}$ & Muito alto \\
\hline I-R3 & Alto & Insalubre & $\begin{array}{c}\text { Eliminação ou redução de riscos } \\
\text { Relocação de moradias }\end{array}$ & Alto \\
\hline BS-R3 & Alto & Baixa salubridade & $\begin{array}{c}\text { Eliminação ou redução de riscos } \\
\text { Relocação de moradias }\end{array}$ & Alto \\
\hline MS-R3 & Alto & Média salubridade & $\begin{array}{l}\text { Eliminação ou redução de riscos } \\
\text { Relocação de moradias }\end{array}$ & Alto \\
\hline S-R3 & Alto & Salubre & $\begin{array}{l}\text { Eliminação ou redução de riscos } \\
\text { Relocação de moradias }\end{array}$ & Alto \\
\hline I-R2 & Médio risco & Insalubre & Relocação de moradias & Alto \\
\hline BS-R2 & Médio risco & Baixa salubridade & Relocação de moradias & Médio \\
\hline MS-R2 & Médio risco & Média salubridade & $\begin{array}{c}\text { Eliminação ou redução de riscos } \\
\text { Relocação de moradias }\end{array}$ & Médio \\
\hline S-R2 & Médio risco & Salubre & $\begin{array}{l}\text { Eliminação ou redução de riscos } \\
\text { Relocação de moradias }\end{array}$ & Baixo \\
\hline I-R1 & Baixo ou sem risco & Insalubre & Melhoria habitacional & Muito alto \\
\hline BS-R1 & Baixo ou sem risco & Baixa salubridade & Melhoria habitacional & Alto \\
\hline MS-R1 & Baixo ou sem risco & Média salubridade & Melhoria habitacional & Baixo \\
\hline S-R1 & Baixo ou sem risco & Salubre & Nenhuma ação & Nenhuma \\
\hline
\end{tabular}

apresentam relevo suavemente ondulado responsável por poucas elevações da topografia, atingindo altitudes sempre inferiores a $70 \mathrm{~m}$.

Entre as áreas de planície e encostas do planalto sedimentar situam-se os aglomerados subnormais Saturnino de Brito e Renascer I, no bairro Trincheiras e Santa Emília de Rodat, em Ilha do Bispo, os quais estão localizados na zona Oeste da cidade de João Pessoa (Figuras 2 e 3).

\section{Aglomerado Saturnino de Brito}

O aglomerado Saturnino de Brito possui uma área de 8,1 hectares e está localizado em uma berma, entre dois taludes. Caracteriza-se pela configuração espacial linear e ocupação desordenada dos topos e das bases dos taludes. O surgimento deste aglomerado foi proporcionado pela topografia favorável em uma estreita faixa de terreno, já que o local consistia em uma berma do talude cortado para a implantação de um emissário de esgotos, que foi projetado e implantado no início do século 20 pelo Engenheiro Saturnino de Brito. É o primeiro aglomerado subnormal da cidade de João Pessoa. Os dados da contagem da população em 2007 indicavam 281 domicílios e uma população absoluta de 1.216 habitantes no aglomerado, equivalente a $14,57 \%$ do bairro Trincheiras (IBGE, 2007).

\section{Aglomerado Renascer I}

Renascer I possui uma área de 5,0 hectares e seu surgimento não ocorreu de forma espontânea. Surgiu a partir da política habitacional implantada pelo Governo do Estado da Paraíba na década de 1980, com característica de conjunto habitacional com quadras e lotes bem definidos e padronização no que se refere à estrutura física dos domicílios. No entanto, há áreas ocupadas de forma espontânea, próximas ao sopé da encosta, devido aos espaços vazios que foram deixados no momento de sua construção. Segundo o Instituto Brasileiro de Geografia e Estatística (IBGE, 2007) a sua população era de 1.558 habitantes em 396 domicílios, representando 18,66\% do bairro Trincheiras.

\section{Aglomerado Santa Emília de Rodat}

O aglomerado Santa Emília de Rodat conta com uma área de 11,5 hectares e situa-se parte em áreas declivosas e naquelas de várzeas do riacho do Pacote. Segundo dados do IBGE (2007), este aglomerado apresentava 215 domicílios com uma população de 801 habitantes, representando 13,17\% do bairro Ilha do Bispo.

\section{Resultados e discussão}

Para a classificação dos riscos nos aglomerados subnormais foram utilizados os dados extraídos do cartograma de riscos, elaborado por Nascimento (2009). Para o aglomerado Santa Emília de Rodat, os riscos não são apenas de deslizamentos, mas também devido às ocorrências de inundações do riacho do Pacote, atingindo diversas moradias. O ICM foi calculado por Nascimento (2009) para os três aglomerados, o que permitiu a análise integrada das variáveis riscos e condições de moradia. 


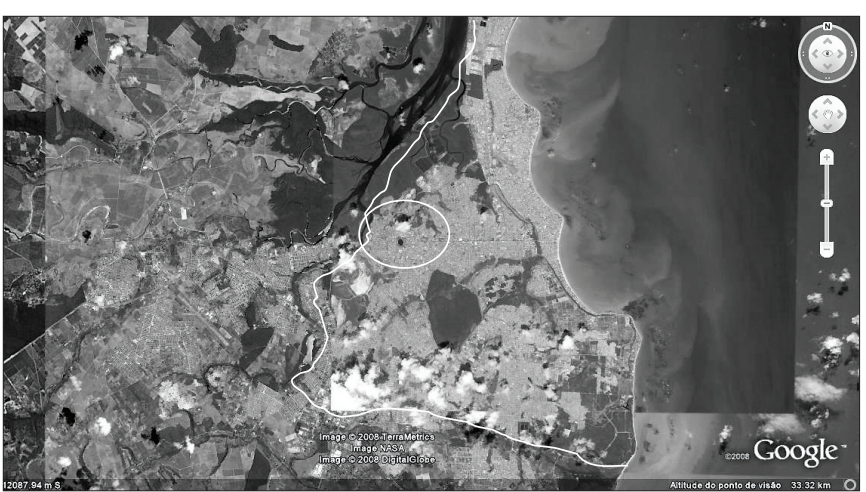

Figura 2 - Localização geográfica das áreas de estudo em João Pessoa, Paraíba.

\section{Análise integrada dos indicadores de riscos e condição de moradia}

A análise integrada dos riscos de deslizamento de encostas e de inundação e das condições de moradia, para amostras representativas dos aglomerados subnormais estudados, é detalhada a seguir. São indicadas as ações mais adequadas a serem prescritas e o grau de prioridade, conforme a metodologia apresentada por Nascimento (2009). Os números das amostras analisadas foram adotados em valores pelo menos $60 \%$ superiores àqueles recomendados pela norma da Associação Brasileira de Normas Técnicas (ABNT, 1985).

No cartograma de riscos elaborado por Nascimento (2009), um conjunto de moradias com riscos apresentando a mesma classificação constitui um trecho. Assim, os diversos trechos, correspondentes aos diferentes riscos, estão representados diferentemente nas figuras a seguir. A Figura 4 apresenta os valores de riscos de deslizamentos e condições de moradia para o aglomerado Saturnino de Brito. Como este se distribui espacialmente em condições de declividades variadas, ocorrem diversos graus de riscos, em 15 trechos, para um total de 80 moradias na amostra.

A Figura 4 mostra uma grande concentração das ocorrências de ICM entre baixa e média salubridade e graus de riscos R3 e R2, ou seja, alto e médio, respectivamente. Para as moradias nos trechos classificados como R3 (trechos 3, 6, 8, 11 e 12), as ações indicadas são de eliminação ou redução dos riscos ou relocação de moradias, com grau de prioridade alto, representando 5,0\% da amostra. Um total de 37,5\% das moradias foi classificado como R2 (trechos 2, 4, 7, 9 e 14), sendo 15,0\% delas com indicação para relocação com graus de prioridades variando de alto a baixo. Àqueles de R4, muito alto (trechos 5, 10, 13 e 15), a indicação foi relocar moradias classificadas como insalubre e de baixa salubridade especificadas $(5,0 \%$ da amostra). Para moradias classificadas como média salubridade $(6,3 \%$ das habitações), a indicação é eliminação ou redução de riscos e/ou relocação da moradia, sendo muito alto o grau de prioridade. Por outro lado, as de baixo ou sem risco e com indicação de melhoria

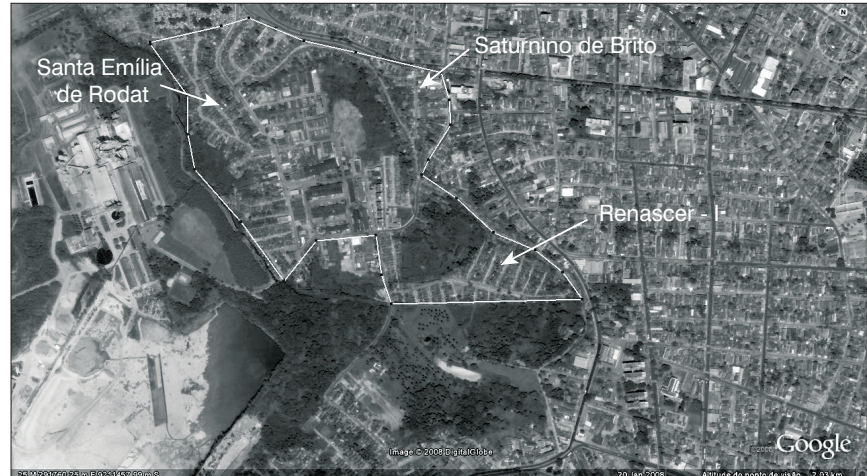

Figura 3 - Detalhes dos aglomerados subnormais Saturnino de Brito, Renascer I e Santa Emília de Rodat em João Pessoa, Paraíba.

habitacional, com grau de prioridade baixo, são apenas 3,7\% do total (trecho 1). Apenas uma no trecho 1 foi classificada como salubre e em área de risco baixo ou sem risco, quadrícula ótima (S-R1), não há indicação de qualquer ação.

A Figura 5 demonstra os cruzamentos das variáveis do ICM e os riscos de deslizamentos para a amostra de 95 residências no Renascer I.

Em tal local, a maior concentração de moradias foi classificada como de risco R1, baixo ou sem risco, nas quadrículas em que o ICM apresentou-se como de baixa, média salubridade e salubres (trecho 4). Logo, são indicadas ações de melhoria habitacional com grau de prioridade baixo para os dois primeiros conjuntos de moradias equivalentes a $73,7 \%$ da amostra, enquanto que as salubres (11,6\%) não receberam indicação de qualquer ação. Relocação, redução ou eliminação de riscos são recomendadas para as moradias classificadas como de risco R3, alto, no trecho 1; e risco $\mathrm{R} 2$, médio, no trecho 2 , totalizando apenas $7,4 \%$ desse aglomerado subnormal, com grau de prioridade variando de alto a baixo. Para as moradias de risco R4, muito alto (trecho 3), 5,3\% da amostra deve ser relocada àquelas classificadas como de baixa salubridade. Referindo-se às situações de média salubridade à salubre, estas ocorrem apenas para duas moradias, tendo indicação de redução ou eliminação dos riscos e/ou relocação com grau de prioridade muito alto.

Para o aglomerado Santa Emília de Rodat, a situação de 80 domicílios amostrados quanto ao risco de deslizamento e às condições de moradia está representada na Figura 6. As habitações classificadas como de risco R1, baixo ou sem risco (trecho 3), somam 80,0\% da amostra, sendo que $8,7 \%$ delas são salubres e não recebem qualquer indicação de ações. As demais do trecho têm designação de melhoria habitacional com prioridade alta à baixa. No que se refere aos domicílios com grau de risco R3, alto (trecho 1), e com condições de moradias variando de baixa salubridade a salubres representando 7,50\% da amostra, a indicação das ações é de relocação, redução ou eliminação dos riscos, com graus de prioridade classificados como alto. Para R2, médio (trecho 2), representando 10,0\% da amostra, as 
ações são as mesmas apresentadas para R3, com graus de prioridade médio e baixo às salubres.

As situações de domicílios quanto aos riscos de inundação e condições das moradias para o aglomerado Santa Emília de Rodat estão representadas na Figura 7. Observa-se que apenas ocorre classificação para os riscos R3 (alto) e R1 (baixo ou sem risco). A distribuição da relação do ICM e os riscos de inundação aos domicílios dos trechos $1(37,5 \%)$ e $2(62,5 \%)$ se apresenta razoavelmente semelhante entre os estados de baixa e média salubridade ou salubres. A maior parte dos domicílios em locais classificados como R3, alto, tem ICM de média salubridade a salubre, representando 50,0\% da amostra, com indicações de ações de relocação, redução ou eliminação de riscos e grau de prioridade alto.

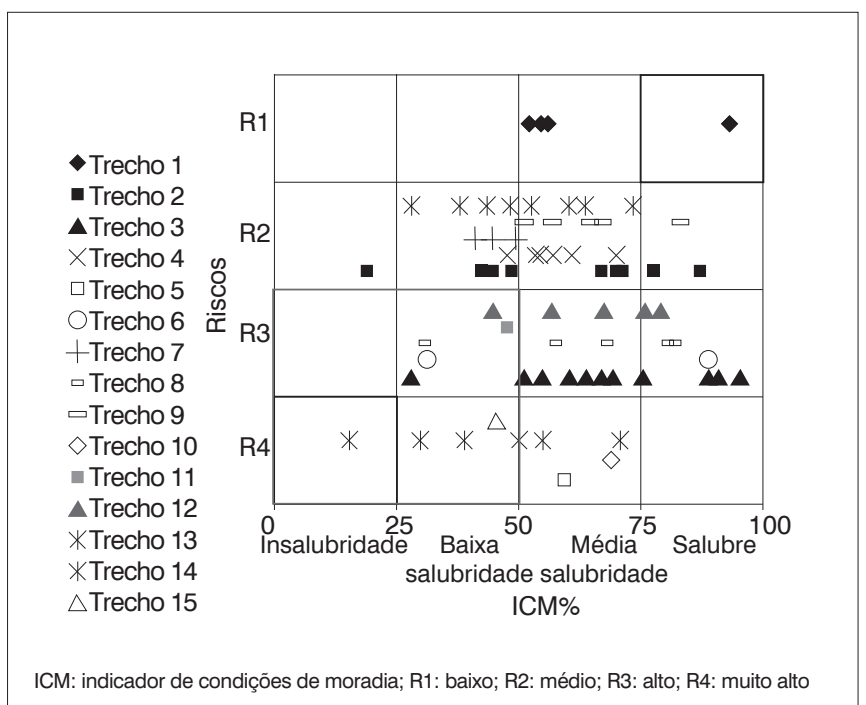

Figura 4 - Cruzamento das variáveis do Indicador de Condições de Moradias e riscos de deslizamentos: aglomerado Saturnino de Brito.

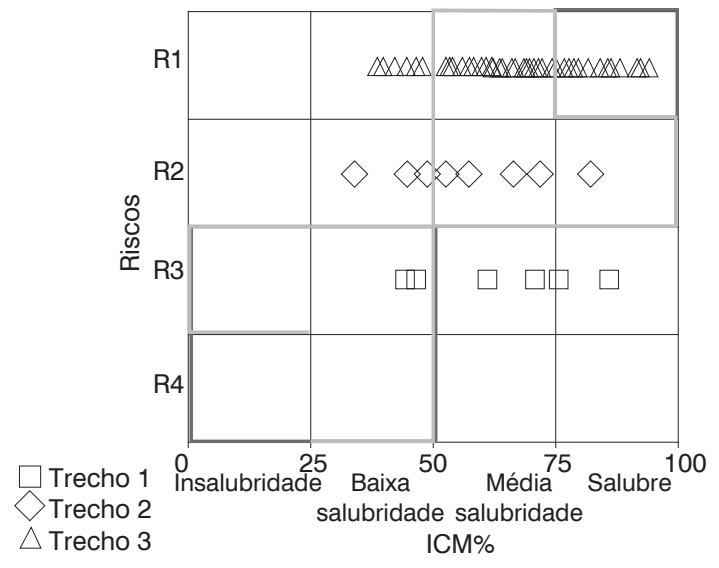

ICM: indicador de condições de moradia; R1: baixo; R2: médio; R3: alto; R4: muito alto.

Figura 6 - Cruzamento das variáveis do Indicador de Condições de Moradias e riscos de deslizamentos: aglomerado Santa Emília de Rodat.

\section{Considerações finais}

Neste trabalho apresentou-se uma metodologia integradora multiobjetivo, que visa essencialmente indicar ações de melhorias habitacionais ou relocação de moradias em áreas sujeitas a riscos de desastres relacionados a fenômenos naturais. Trata-se de um novo método para o auxílio à tomada de decisão a fim de executar políticas públicas de requalificações urbanística e ambiental em aglomerados subnormais, contemplando conjuntamente o binômio: condições de moradia e riscos de desastres.

Para sua aplicação, necessita-se o mapeamento dos riscos de desastres e da determinação de condições físicas das moradias abrangendo aspectos de qualidade e densidade habitacionais. Foi construída no sentido de oferecer opções de ações adequadas na forma mais

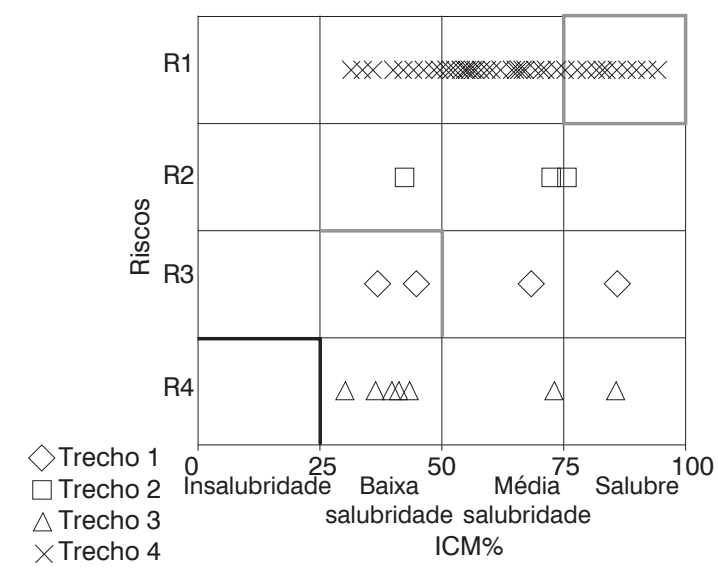

ICM: indicador de condições de moradia; R1: baixo; R2: médio; R3: alto; R4: muito alto.

Figura 5 - Cruzamento das variáveis do Indicador de Condições de Moradia e riscos de deslizamentos: aglomerado Renascer I.

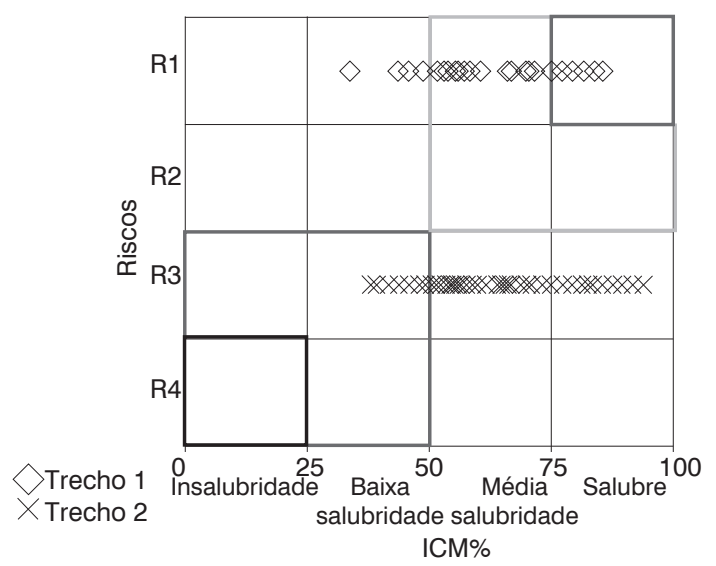

ICM: indicador de condições de moradia; R1: baixo; R2: médio; R3: alto; R4: muito alto.

Figura 7 - Cruzamento das variáveis do Indicador de Condições de Moradia e riscos de inundações: aglomerado Santa Emília de Rodat. 
simples possível, inclusive quanto ao grau de prioridade, com uso de gráfico e quadro indicativo.

A análise integrada realizada, com base na elaboração dos gráficos de coordenadas cartesianas, representando as condições de moradia e o grau de risco, pode se revelar como uma importante ferramenta para a compreensão dos estados destas variáveis em uma visão holística e permite fazer inferências quanto à priorização de ações de melhoria habitacional, eliminação ou redução de riscos e relocação de moradias.

Como exemplos foram apresentadas aplicações em três aglomerados subnormais na cidade de João Pessoa, Paraíba, em que, à luz da metodologia desenvolvida, são indicadas ações de relocação ou melhoria habitacional e redução ou eliminação de riscos, além da recomendação de não se realizar nada, conforme o caso, além do grau de prioridade delas.

A importância desta metodologia está na versatilidade em oferecer aos gestores públicos opções, com o intuito de minimizar os riscos em áreas vulneráveis ocupadas com aglomerados subnormais como também de melhorar a salubridade das moradias para que seja compatível com os recursos disponíveis ou a serem disponibilizados pelas diversas instâncias governamentais ou mesmo não-governamentais.

\section{Referências}

ANJOS, B.L.; COSTA, A.M.; ANJOS, D.L. (2010) Chuvas diárias em João Pessoa, uma contribuição para a Defesa Civil. In: Congresso Brasileiro de Meteorologia, 16, Belém, Pará, 13 a 17 de setembro. Anais... Rio de Janeiro: Sociedade Brasileira de Meteorologia.

ASSOCIAÇÃO BRASILEIRA DE NORMAS TÉCNICAS (ABNT). (1985) NBR 5426: Plano de amostragem e procedimentos na inspeção por atributos. Rio de Janeiro.

BRASIL. Ministério das Cidades, Secretaria de Programas Urbanos. (2006) Capacitação em mapeamento e gerenciamento de risco. Ministério das Cidades, Universidade Federal de Santa Catarina, Centro de Estudos e Pesquisa sobre Desastres, Instituto de Pesquisas Tecnológicas (IPT), 122 p. +CD-ROM.

INSTITUTO BRASILEIRO DE GEOGRAFIA E ESTATÍSTICA (IBGE). (2007) Contagem da população 2007. Rio de Janeiro: IBGE.

NASCIMENTO, M.O.T. (2009) Desenvolvimento de metodologias de priorização de intervenções físicas em aglomerados subnormais sujeitas a riscos de desastres. 139 p. Dissertação (Mestrado) Programa de Pós-Graduação em Engenharia Urbana e Ambiental, Centro de Tecnologia, Universidade Federal da Paraíba, João Pessoa.
PRESTES, E.M.T. (2004) Aspectos do envolvimento público e técnicas de previsão e análise das tendências dos processos de gestão por Emilia Maria de Trindade Prestes. In: SANTOS, C.A.G.; BRAGA, C.F.C.; FACUNDO, I.D.; RUFINO, I.A.A.; DANTAS NETO, J.; RIOS, M.R.; CURI, R.C.; CABRAL DA SILVA, T. Gestão de recursos hídricos: gerenciamento de bacias hidrográficas. Universidade Federal de Campina Grande, Universidade Federal da Paraíba, Unesco, 231 p.

SILVA, N.V.S. (2006) As condições de salubridade ambiental das comunidades periurbanas da bacia do baixo Gramame: diagnóstico e proposição de benefícios, 122 p. Dissertação (Mestrado) - Universidade Federal da Paraíba, Centro de Tecnologia, Programa de Pós-graduação em Engenharia Urbana e Ambiental, João Pessoa.

ORGANIZAÇÃO DAS NAÇÕES UNIDAS PARA A EDUCAÇÃO, A CIÊNCIA E A CULTURA (UNESCO). (1987) Methodological guidelines for the integrated environmental evaluation of water resources development. Projeto FP/5201-85-01/UNEP - Ludwig Hartmann (coord.). Paris: United Nations Educational, Scientific and Cultural Organization, 152 p.

VARGAS, J.E. (2002) Políticas públicas para la reducción de la vulnerabilidad frente a los desastres naturales y socio-naturales. Santiago de Chile: Naciones Unidas, División de Medio Ambiente y Asentamientos Humanos, CEPAL - Serie Medio ambiente e desarrollo, 50. 